\title{
Vitamin D, Race, and Cardiovascular Mor- tality: Findings From a National US Sample
}

\author{
Kevin Fiscella, MD, MPH \\ Peter Franks, $M D^{2}$ \\ 'Department of Family Medicine and \\ Department of Community \& Preventive \\ Medicine, University of Rochester School \\ of Medicine and Dentistry, Rochester, \\ New York \\ ${ }^{2}$ Center for Healthcare Policy and Research, \\ and Department of Family and Community \\ Medicine, University of California at Davis, \\ Davis, California
}

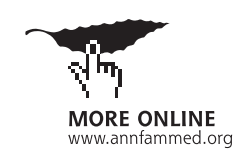

Conflicts of interest: none reported

\section{CORRESPONDING AUTHOR}

Kevin Fiscella, MD, MPH

1381 South Ave

Rochester, NY 14620

Kevin_Fiscella@URMC.rochester.edu

\begin{abstract}
PURPOSE Findings are conflicting about the relationship between vitamin $D$ levels and cardiovascular mortality. We wanted to determine the contribution of vitamin D levels to black-white disparities in cardiovascular mortality.

METHODS We examined the association of serum 25(OH)D levels with cardiovascular mortality and its contribution to elevated risk among blacks through a retrospective cohort using baseline data from the third National Health and Nutrition Examination Survey 1988-1994 and cause-specific mortality through 2001 using the National Death Index. Using piecewise Poisson regression models, we examined the risk of cardiovascular death (coronary heart disease, heart failure, and stroke) by sample 25(OH)D quartile, adjusting for cardiovascular risk factors, and compared models of adjusted race-related cardiovascular mortality with and without further adjustment for 25(OH)D levels.
\end{abstract}

RESULTS Participants with 25(OH)D levels in the lowest quartile (mean $=13.9$ $\mathrm{ng} / \mathrm{mL}$ ) compared with those in the 3 higher quartiles (mean $=21.6,28.4$, and $41.6 \mathrm{ng} / \mathrm{mL}$ ) had higher adjusted risk of cardiovascular death (incident rate ratio $[I R R]=1.40 ; 95 \%$ confidence interval $[\mathrm{Cl}], 1.16-1.70)$. The higher age- and sex-adjusted cardiovascular mortality observed in blacks vs whites (IRR $=1.38$; $95 \% \mathrm{Cl}, 1.13-1.70$ ) was attenuated (IRR $=1.14 ; 95 \% \mathrm{Cl}, 0.91-1.44)$ by adjustment for 25(OH)D levels and fully eliminated with further adjustment for income $(\mathrm{IRR}=1.01 ; 95 \% \mathrm{Cl}, 0.82-1.24)$.

CONCLUSIONS Low serum levels of 25(OH)D are associated with increased cardiovascular mortality in a nationally representative US sample. Black-white differences in 25(OH)D levels may contribute to excess cardiovascular mortality in blacks. Interventional trials among persons with low vitamin D levels are needed to determine whether oral supplementation improves cardiovascular outcomes.

Ann Fam Med 2010;8:11-18. doi:10.1370/afm.1035.

\section{INTRODUCTION}

vidence links low levels of vitamin D, particularly levels of 25, hydroxyvitamin $\mathrm{D}$, or $25[\mathrm{OH}] \mathrm{D}$, to cardiovascular disease. ${ }^{1,2}$ Low serum levels (and/or low dietary and supplement intake) have been linked to cardiovascular risk factors that include obesity, ${ }_{1}^{3,4}$ hypertension, ${ }^{3,5,6}$ diabetes ${ }_{,}^{3,7}$ peripheral arterial disease, ${ }^{8}$ chronic renal disease, ${ }^{9}$ and heart disease. Studies have also linked low levels to incident cardiovascular disease, ${ }^{10}$ including myocardial infarction. ${ }^{11}$

Low levels of vitamin D may alter the renin-angiotensin axis by direct suppression of renin gene expression ${ }^{12}$; affect vascular endothelium through smooth muscle proliferation, ${ }^{13}$ inflammation, ${ }^{12}$ and thrombosis ${ }^{14}$; alter calcium channel fluxes; and induce secondary hyperparathyrodism. Elevated parathyroid hormone has been linked to mortality in the elderly, ${ }_{1}^{15}$ possibly through vascular effects, ${ }^{16}$ although findings regarding an association with cardiovascular mortality have been mixed. ${ }^{17,18}$ These findings suggest pathways through which low levels of vitamin D may increase the risk of cardiovascular-related morbidity (including hyperten- 
sion, diabetes, renal, heart and cerebrovascular disease) and subsequent cardiovascular mortality.

Relative to whites, blacks have higher rates of many cardiovascular risk factors and higher age- and sexadjusted cardiovascular mortality. ${ }^{19}$ This higher risk is accounted for by traditional risk factors (many of which are more common among blacks) and by lower socioeconomic status (itself associated with traditional cardiovascular risk factors). ${ }^{20,21}$ Low-socioeconomic status is associated with greater chronic stress, poorer access to health care, and fewer resources for ameliorating behavioral risk factors. Blacks have significantly lower mean serum $25(\mathrm{OH}) \mathrm{D}$ levels, ${ }^{3,22}$ related both to biological (increased skin pigmentation reducing activation of oral vitamin $\mathrm{D}^{23}$ ) and social and behavioral (lower intake, ${ }^{24}$ less sun exposure ${ }^{25}$ ) factors. Thus, lower levels of $25(\mathrm{OH}) \mathrm{D}$ may contribute to blackwhite disparities in cardiovascular mortality acting through racial differences in both biological and social or behavioral factors that increase the risk of cardiovascular-related conditions and subsequent mortality.

We examined whether (1) serum $25(\mathrm{OH}) \mathrm{D}$ predicts subsequent cardiovascular mortality among a representative sample of US adults, and (2) differences in 25(OH)D levels contribute to black-white differences in age- and sex-adjusted cardiovascular mortality.

\section{METHODS}

\section{Participants}

We constructed a retrospective cohort using publicly available data from the nationally representative Third National Health and Nutrition Examination Survey (NHANES III) conducted from 1988-1994. ${ }^{26}$ Our sample was restricted to participants aged 18 years and older. Complete data for all variables (including vital status) were available on 15,363 (78.3\%) persons, corresponding to $90.8 \%$ of the target population (weighted).

\section{Vitamin D}

Serum 25(OH)D was measured using a radioimmunoassay kit (DiaSorin, Stillwater, Minnesota). ${ }^{27} \mathrm{Lev}$ els were categorized into quartiles based on the unweighted sample. Although 1,25-dihydroxyvitamin $\mathrm{D}$ is the biologically active form of vitamin $\mathrm{D}$, serum $25(\mathrm{OH}) \mathrm{D}$ is regarded as the best indicator of vitamin $\mathrm{D}$ status in individuals without kidney disease. ${ }^{10}$

\section{Race and Ethnicity}

We assessed race and ethnicity based on self-reported race (white, black, or other) and self-reported ethnicity (Hispanic or not). We classified participants as white (non-Hispanic), black (non-Hispanic), Hispanic, and other.

\section{Cardiovascular Deaths}

Assessment of death continued from data collection until December 31, 2000, based on the NHANES III Linked Mortality file, using International Classification of Diseases, 10th Revision (ICD-10) 3-digit codes. ${ }^{28}$ Cardiovascular mortality was based on codes I11-I78 (excluding I33-I40 [carditis]). Follow-up was censored at the date of death for persons who died of other diseases and at December 31, 2000, for those not identified as deceased.

\section{Other Measures}

We also collected data on additional measures that affect cardiovascular health: physical activity based on metabolic equivalent tasks (METs), body mass index (BMI), smoking status, poverty level, total cholesterol, serum creatinine, systolic blood pressure, serum albumin, albuminuria, $\mathrm{C}$-reactive protein (CRP), glomerular filtration rate (eGFR), albumin-creatinine ratio (ACR), fasting blood glucose, and self-reported health, diabetes, and cardiovascular health. Details of these and supplementary measures and analyses are described in the Supplemental Appendix, available at: http:// www.annfammed.org/cgi/content/full/8/1/11/DC1.

\section{Statistical Analyses}

Analyses were conducted with Stata (version 10.0, StataCorp, College Station, Texas), adjusting for the complex survey design of NHANES III to yield appropriate standard errors and population parameter estimates. We implemented Cox semiparametric proportional hazards survival analyses and compared these results with a proportional hazards parametric regression model of age-at-event failure time data specified as a log-linear model. ${ }^{29}$ This latter model was implemented by applying a piecewise Poisson regression procedure, using person years as the unit of analysis. That is, each subject contributed an observation for each full or partial year of follow-up. Instead of the adjusted hazard ratios (HRs) available from Cox regression, the Poisson regression yields adjusted incident rate ratios (IRRs); IRRs were quite similar to the HRs. An advantage of the parametric Poisson regression model is that, unlike the semiparametric Cox model, it allows formal statistical comparison of parameter estimates among nested models. ${ }^{30}$ We tested the proportionality assumption graphically and numerically and found no concerns. We report the Poisson model results. Cox model results are available on request.

The analysis examining the adjusted relationship between serum $25(\mathrm{OH}) \mathrm{D}$ and cardiovascular mortality controlled for age, log (age) (to adjust for the exponential relationship between age and mortality), sex, interview month (a series of dummy variables), 
region (a series of dummy variables), race and ethnicity (white, black, Hispanic, and other), household income using percentage of federal poverty level $(<100 \%, 100 \%-149 \%$, $150 \%-199 \%$, 200\%-299\%, $\geq 300 \%$ ), smoking status (current or not), physical inactivity (METs <3.5/mo), self-rated health (excellent, very good, good, fair, poor), self-reported diabetes (based on self-report, a fasting glucose $>126 \mathrm{mg} / \mathrm{dL}$, or glycohemoglobin $>6.0 \%$ ), selfreported baseline cardiovascular disease, BMI category $(<20$, 20-25, 25.1-29.9, $\left.\geq 30 \mathrm{~kg} / \mathrm{m}^{2}\right)$, systolic blood pressure $(<120$, 120-139, $\geq 140$ mm Hg), eGFR $\left(\mathrm{mL} / \mathrm{min}\right.$ per $\left.1.73 \mathrm{~m}^{2}\right)$, total cholesterol $(<200,200-239$, 240-279, $\geq 280 \mathrm{mg} / \mathrm{dL}$ ), serum albumin (mg/dL), CRP, urinary ACR, and serum 25(OH)D (as sample quartiles with cut points of $<18,18-24.9,25-31.9$, and $\geq 32 \mathrm{ng} / \mathrm{mL}^{*}$ to examine possible threshold effects).

To examine the possible contribution of serum $25(\mathrm{OH}) \mathrm{D}$ to black-white differences in cardiovascular mortality, we used a nested modeling approach, examining 4 models. Because many of the covariates included above may themselves be in the pathway that connects race, vitamin D, and cardiovascular mortality (as noted in the introduction), we conducted an analysis that included only those exogenous variables unlikely to mediate the effects of $25(\mathrm{OH}) \mathrm{D}$ levels on cardiovascular mortality (age, log [age], sex, region, and month of examination). We compared that model to a model that also included serum $25(\mathrm{OH}) \mathrm{D}$ (to derive an upper estimate of the potential mediating effect of $25[\mathrm{OH}] \mathrm{D})$, another that included percentage of poverty (to derive an upper estimate of the potential mediating effect of income), and finally, one with both $25(\mathrm{OH}) \mathrm{D}$ and poverty (to estimate the separate medi-

* To convert to SI units (nmol/L), multiply by 2.496 .
Table 1. Distribution of Characteristics (Means, Proportions) by Quartiles of Plasma 25(OH)D

\begin{tabular}{|c|c|c|c|c|c|}
\hline \multirow[b]{2}{*}{ Characteristics } & \multirow{2}{*}{$\begin{array}{c}\text { Overall } \\
\text { Mean or } \\
\text { Proportion }\end{array}$} & \multicolumn{4}{|c|}{ Quartiles of $25(\mathrm{OH}) \mathrm{D}$} \\
\hline & & $<25$ th & 25-49th & $50-74$ th & 75-100th \\
\hline 25(OH)D, range, ng/mL & & $<18$ & $18-24.9$ & $25-31.9$ & $>32$ \\
\hline 25(OH)D, mean, ng/mL & 29.64 & 13.90 & 21.60 & 28.44 & 41.63 \\
\hline Age, mean, y & 43.64 & 45.55 & 45.83 & 44.53 & 40.89 \\
\hline Male & 0.48 & 0.34 & 0.44 & 0.49 & 0.55 \\
\hline \multicolumn{6}{|l|}{ Race/ethnicity } \\
\hline White & 0.77 & 0.48 & 0.68 & 0.82 & 0.91 \\
\hline Black & 0.10 & 0.33 & 0.13 & 0.06 & 0.02 \\
\hline Hispanic & 0.09 & 0.13 & 0.13 & 0.10 & 0.06 \\
\hline Other & 0.03 & 0.06 & 0.05 & 0.03 & 0.01 \\
\hline \multicolumn{6}{|l|}{ Poverty level } \\
\hline$<100 \%$ & 0.12 & 0.18 & 0.13 & 0.11 & 0.09 \\
\hline $100 \%-150 \%$ & 0.10 & 0.12 & 0.11 & 0.08 & 0.09 \\
\hline $150 \%-200 \%$ & 0.13 & 0.14 & 0.13 & 0.12 & 0.13 \\
\hline $200 \%-300 \%$ & 0.23 & 0.21 & 0.23 & 0.23 & 0.23 \\
\hline$>300 \%$ & 0.43 & 0.35 & 0.40 & 0.46 & 0.46 \\
\hline Current smoker & 0.28 & 0.32 & 0.27 & 0.26 & 0.29 \\
\hline Exercise, METs <3.5/mo & 0.17 & 0.31 & 0.21 & 0.16 & 0.10 \\
\hline BMI, mean, $\mathrm{kg} / \mathrm{m}^{2}$ & 26.43 & 28.00 & 27.42 & 26.37 & 25.25 \\
\hline Systolic BP, mean, mm Hg & 121.98 & 124.31 & 123.58 & 122.08 & 119.77 \\
\hline Total cholesterol, mean, mg/dL & 202.96 & 204.32 & 206.00 & 201.64 & 201.42 \\
\hline Serum albumin, mean, mg/dL & 4.19 & 4.09 & 4.15 & 4.21 & 4.24 \\
\hline C-reactive protein, mean, mg/L & 0.41 & 0.49 & 0.42 & 0.42 & 0.36 \\
\hline eGFR, mean, $\mathrm{mL} / \mathrm{min}$ per $1.73 \mathrm{~m}^{2}$ & 93.72 & 98.77 & 93.32 & 93.42 & 92.24 \\
\hline Urinary $A C R$, mean & 0.25 & 0.48 & 0.24 & 0.21 & 0.18 \\
\hline \multicolumn{6}{|l|}{ Self-rated health } \\
\hline Excellent & 0.20 & 0.15 & 0.18 & 0.21 & 0.23 \\
\hline Very good & 0.32 & 0.24 & 0.28 & 0.33 & 0.36 \\
\hline Good & 0.33 & 0.39 & 0.35 & 0.32 & 0.30 \\
\hline Fair & 0.13 & 0.17 & 0.16 & 0.12 & 0.09 \\
\hline Poor & 0.03 & 0.04 & 0.03 & 0.02 & 0.02 \\
\hline Diabetes & 0.10 & 0.17 & 0.12 & 0.10 & 0.07 \\
\hline Baseline CV morbidity & 0.03 & 0.04 & 0.04 & 0.03 & 0.03 \\
\hline Chronic kidney disease & 0.05 & 0.06 & 0.06 & 0.05 & 0.04 \\
\hline \multicolumn{6}{|c|}{$\begin{array}{l}\mathrm{ACR}=\text { albumin-creatinine ratio; } \mathrm{BMI}=\text { body mass index; } \mathrm{BP}=\text { blood pressure; } \mathrm{CV}=\text { cardiovascular; } 25(\mathrm{OH}) \mathrm{D}=25, \\
\text { hydroxyvitamin } \mathrm{D} ; \mathrm{eGFR}=\text { estimated glomerular filtration rate; } \mathrm{MET}=\text { metabolic equivalent task. }\end{array}$} \\
\hline \multicolumn{6}{|c|}{ Note: Values are weighted to produce national estimates. } \\
\hline a Numbers are proportions except whe & dicated as mea & & & & \\
\hline
\end{tabular}

ating effects of $25[\mathrm{OH}] \mathrm{D}$ and income on the relationship between race and cardiovascular mortality). Comparisons among models were conducted using the method of Clogg et al. ${ }^{30}$ Confidence intervals around percentage of mediation effect were derived using Fieller's method. ${ }^{31}$

\section{RESULTS}

The mean serum 25(OH)D level in the sample was $29.5 \mathrm{ng} / \mathrm{mL}$. Table 1 displays the distribution of baseline characteristics by sample quartile of $25(\mathrm{OH}) \mathrm{D}$ 


\begin{tabular}{|c|c|c|}
\hline Characteristic & IRR & $95 \% \mathrm{Cl}$ \\
\hline \multicolumn{3}{|c|}{$25(\mathrm{OH}) \mathrm{D}$ quartiles (reference $<25$ th quartile) } \\
\hline 25-49th & 0.71 & $0.54-0.94$ \\
\hline $50-74$ th & 0.65 & $0.53-0.79$ \\
\hline$\geq 75$ th & 0.79 & $0.62-1.01$ \\
\hline Age, years & 1.15 & 1.11-1.18 \\
\hline Log (age) & 0.04 & $0.01-0.20$ \\
\hline Male & 2.38 & $1.92-2.96$ \\
\hline \multicolumn{3}{|l|}{ Race/ethnicity (reference white) } \\
\hline Black & 0.81 & $0.65-1.01$ \\
\hline Hispanic & 0.53 & $0.37-0.76$ \\
\hline Other & 0.83 & $0.33-2.04$ \\
\hline \multicolumn{3}{|c|}{ Poverty level (reference $<100 \%$ poverty level) } \\
\hline $100 \%-149 \%$ & 0.95 & $0.66-1.37$ \\
\hline $150 \%-199 \%$ & 0.99 & $0.73-1.36$ \\
\hline $200 \%-299 \%$ & 0.93 & $0.71-1.23$ \\
\hline$\geq 300 \%$ & 0.82 & $0.59-1.13$ \\
\hline Current smoker & 1.55 & $1.25-1.92$ \\
\hline No exercise (METs <3.5/mo) & 1.29 & $1.04-1.59$ \\
\hline \multicolumn{3}{|l|}{ BMI category (reference $<20 \mathrm{~kg} / \mathrm{m}^{2}$ ) } \\
\hline $20.0-24.9 \mathrm{~kg} / \mathrm{m}^{2}$ & 0.64 & $0.45-0.91$ \\
\hline $25.0-29.9 \mathrm{~kg} / \mathrm{m}^{2}$ & 0.62 & $0.46-0.83$ \\
\hline$\geq 30.0 \mathrm{~kg} / \mathrm{m}^{2}$ & 0.63 & $0.41-0.97$ \\
\hline \multicolumn{3}{|c|}{ Systolic blood pressure (reference <120 mm Hg) } \\
\hline $120-139 \mathrm{~mm} \mathrm{Hg}$ & 1.38 & $1.01-1.89$ \\
\hline$>140 \mathrm{~mm} \mathrm{Hg}$ & 1.40 & $1.02-1.91$ \\
\hline \multicolumn{3}{|l|}{ Total cholesterol (reference $<200 \mathrm{mg} / \mathrm{mL}$ ) } \\
\hline $200-239 \mathrm{mg} / \mathrm{mL}$ & 1.04 & $0.80-1.34$ \\
\hline $240-279 \mathrm{mg} / \mathrm{mL}$ & 1.37 & $1.10-1.70$ \\
\hline$\geq 280 \mathrm{mg} / \mathrm{mL}$ & 1.12 & $0.86-1.45$ \\
\hline Serum albumin, mg/dL & 0.80 & $0.55-1.17$ \\
\hline Log (C-reactive protein) & 1.14 & $1.02-1.26$ \\
\hline eGFR, mL/min per $1.73 \mathrm{~m}^{2}$ & 0.99 & $0.98-1.00$ \\
\hline Log (urinary albumin-creatinine ratio) & 1.24 & $1.16-1.33$ \\
\hline \multicolumn{3}{|l|}{ Self-rated health (reference excellent) } \\
\hline Very good & 1.22 & $0.89-1.66$ \\
\hline Good & 1.37 & $0.97-1.92$ \\
\hline Fair & 1.70 & $1.09-2.65$ \\
\hline Poor & 2.49 & $1.63-3.80$ \\
\hline Diabetes & 1.24 & $1.00-1.53$ \\
\hline Baseline cardiovascular morbidity & 2.08 & $1.68-2.58$ \\
\hline Chronic kidney disease & 1.05 & $0.79-1.40$ \\
\hline \multicolumn{3}{|c|}{$\begin{array}{l}\mathrm{BMI}=\text { body mass index; } \mathrm{Cl}=\text { confidence interval } ; 25(\mathrm{OH}) \mathrm{D}=25 \text {, hydroxyvitamin } \mathrm{D} ; \\
\text { eGFR = estimated glomerular filtration rate; } \mathrm{MET}=\text { metabolic equivalency task. }\end{array}$} \\
\hline $\begin{array}{l}\text { Note: IRRs are based on a fully adjusted mo } \\
\text { baseline evaluation, and region. }\end{array}$ & iable & ble, month of \\
\hline
\end{tabular}

health, less diabetes, and less baseline cardiovascular morbidity.

There were 933 (43.7\% of total mortality, population weighted) cardiovascular deaths among those with no missing data in 138,549 person-years of follow-up. Of the cardiovascular deaths, 25\% were due to myocardial infarctions, $44 \%$ were due to ischemic and other heart disease, and $17 \%$ were due to stroke.

The adjusted association of risk factors with cardiovascular death is summarized in Table 2. Cardiovascular death was independently associated with older age, male sex, non-Hispanic ethnicity, higher blood pressure, smoking, physical inactivity, being underweight (BMI $<20.0 \mathrm{~kg} / \mathrm{m}^{2}$ ), higher total cholesterol, higher CRP, lower eGFR, higher ACR, poorer selfrated health, and baseline diabetes and cardiovascular morbidity.

Higher 25(OH)D levels (relative to the lowest quartile) were associated with lower adjusted mortality (Figure 1). There appeared to be a threshold effect with little reduction in cardiovascular deaths above the 25 th percentile. Cardiovascular mortality in the highest $25(\mathrm{OH}) \mathrm{D}$ quartile was higher than that in the 2 middle quartiles, but differences among the higher 3 quartiles were not statistically significant (adjusted Wald test, $F_{2,48}=1.37$, $P=.26$ ). The adjusted cardiovascular mortality risk for the lowest compared with the higher three $25(\mathrm{OH}) \mathrm{D}$ quartiles was $40 \%$ higher (IRR 1.40 (95\% confidence interval [CI], 1.16-1.69, $P=.001)$. An analysis excluding those with baseline cardiovascular-related morbidity (diabetes, cardiovascular disease, and eGFR $<60 \mathrm{~mL} / \mathrm{min}$ per $1.73 \mathrm{~m}^{2}$ ) revealed an adjusted IRR for low 25(OH)D of 1.97 (95\% CI, 1.40-2.78, P<.001).

We addressed our second aim, examining the relationship between race and cardiovascular mortality, and the potential mediating effect of $25(\mathrm{OH}) \mathrm{D}$ in a series of nested models (Table 3 ). In the model adjusting only for exogenous variables (ie, those more clearly outside the causal pathway between $25(\mathrm{OH}) \mathrm{D}$ and cardiovascular mortality): age, log (age), sex, month, and region, blacks showed sig-

levels. Sixteen percent of the target population had $25(\mathrm{OH}) \mathrm{D}$ levels in the lowest sample quartile. Higher plasma $25(\mathrm{OH}) \mathrm{D}$ levels were associated with younger age, being male or white, higher income, lower blood pressure, not smoking, a lower BMI, a lower total cholesterol or serum albumin, higher eGFR, lower ACR, lower CRP, greater physical activity, better self-rated nificantly higher cardiovascular mortality than whites (Table 3, model 1). When 25(OH)D (Table 3, model 2) was added, there was a significant reduction in the risk associated with black race $\left(F_{1,49}=24.9(), P<.001\right)$. The proportional excess risk reduction for race ([IRR(BlackM1)-IRR(BlackM2)]/[IRR(BlackM1)-1]) between model 1 and 2 was $63 \%$ (95\% CI, 35\%-100\%). 
Figure 1. Adjusted incidence rate ratio (IRR) for quartiles of plasma 25(OH)D levels with lowest quartile as reference (IRR $=1$ ).

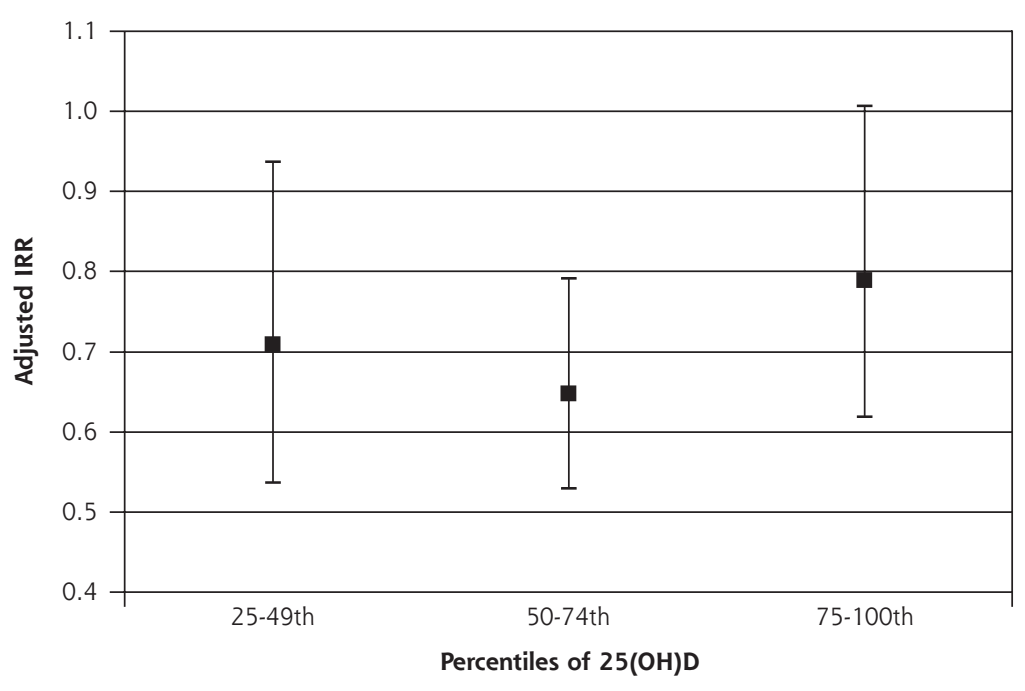

$25(\mathrm{OH}) \mathrm{D}=25$, hydroxyvitamin $\mathrm{D}$

Table 3. Incident Rate Ratios (IRR) For Death From Cardiovascular Disease During Follow-up Interval With Selected Adjustment

\begin{tabular}{|c|c|c|}
\hline & IRR & $95 \% \mathrm{Cl}$ \\
\hline \multicolumn{3}{|l|}{ Model 1} \\
\hline \multicolumn{3}{|c|}{ Race (reference white) } \\
\hline Black & 1.38 & $1.13-1.70$ \\
\hline \multicolumn{3}{|l|}{ Model 2} \\
\hline \multicolumn{3}{|c|}{ Race (reference white) } \\
\hline Black & 1.14 & $0.91-1.44$ \\
\hline \multicolumn{3}{|c|}{ 25(OH)D quartile (reference highest quartile) } \\
\hline Low $25(\mathrm{OH}) \mathrm{D}$ & 1.73 & $1.44-2.09$ \\
\hline \multicolumn{3}{|l|}{ Model 3} \\
\hline \multicolumn{3}{|c|}{ Race (reference white) } \\
\hline Black & 1.20 & $0.99-1.46$ \\
\hline \multicolumn{3}{|c|}{ Poverty level (reference <100\%) } \\
\hline $100 \%-149 \%$ & 0.96 & $0.69-1.34$ \\
\hline $150 \%-199 \%$ & 1.03 & $0.74-1.43$ \\
\hline $200 \%-299 \%$ & 0.69 & $0.54-0.88$ \\
\hline$>300 \%$ & 0.55 & $0.43-0.71$ \\
\hline \multicolumn{3}{|l|}{ Model 4} \\
\hline \multicolumn{3}{|c|}{ Race (reference white) } \\
\hline Black & 1.01 & $0.82-1.24$ \\
\hline \multicolumn{3}{|c|}{ Poverty level (reference <100\%) } \\
\hline $100 \%-149 \%$ & 0.98 & $0.70-1.37$ \\
\hline $150 \%-199 \%$ & 1.05 & $0.75-1.46$ \\
\hline $200 \%-299 \%$ & 0.72 & $0.56-0.91$ \\
\hline$>300 \%$ & 0.56 & $0.44-0.73$ \\
\hline \multicolumn{3}{|c|}{ 25(OH)D (reference highest quartile) } \\
\hline Low $25(\mathrm{OH}) \mathrm{D}$ & 1.70 & $1.43-2.03$ \\
\hline \multicolumn{3}{|c|}{$25(\mathrm{OH}) \mathrm{D}=25$, hydroxyvitamin $\mathrm{D}$. } \\
\hline \multicolumn{3}{|c|}{$\begin{array}{l}\text { Note: All models adjusted for age, log (age), sex, region, and month of baseline evaluation. Model } 1 \\
\text { adjusts for race, model } 2 \text { adjusts for race and serum } 25(\mathrm{OH}) \mathrm{D} \text { (lowest quartile vs others), model } 3 \text { adjusts } \\
\text { for race and poverty level, and model } 4 \text { adjusts for race, poverty level, and serum } 25(\mathrm{OH}) \mathrm{D} \text {. }\end{array}$} \\
\hline
\end{tabular}

When income was added to the model (Table 3, model 3), there was a significant reduction in the risk associated with black race (between the exogenous variable only model 1 and model 3, including income, $F=14.7 ; P<.001)$. When both income and $25(\mathrm{OH}) \mathrm{D}$ were added to the exogenous variables (Table 3 , model 4), the point estimate for race was further reduced, this time to 1.0. The reductions in the IRR for race were significant between model 2 and $4(F=11.2 ; P=.002)$ and between model 3 and $4(F=28.9$; $P<.001)$, indicating that the effects of income and $25(\mathrm{OH}) \mathrm{D}$ were additive.

\section{DISCUSSION}

Our findings are notable in 2 respects. First, consistent with prior research, we observed an association between baseline low serum $25(\mathrm{OH}) \mathrm{D}$ levels and subsequent increased cardiovascular mortality. This association appeared to be partly mediated though cardiovascular-related conditions (hypertension, heart failure, myocardial infarction, stroke, kidney disease, and diabetes), but it was also observed when controlling for multiple existing cardiovascular risk factors, including many potential mediators. Second, we observed that low $25(\mathrm{OH}) \mathrm{D}$ levels substantially accounted for the higher age- and sex-adjusted cardiovascular mortality among blacks. We address both these findings in the context of the existing literature and study limitations.

In this nationally representative US sample, participants in the bottom sample quartile for serum $25(\mathrm{OH}) \mathrm{D}$ had $40 \%$ adjusted higher cardiovascular risk for death than those with higher levels. There appeared to be a threshold effect, with no evidence of further effects above the lowest quartile. In the supplemental analysis (shown in the Supplemental Appendix), lower vitamin $\mathrm{D}$ intake was associated with 
higher cardiovascular mortality; this association was no longer significant when $25(\mathrm{OH}) \mathrm{D}$ was included. These results add to existing evidence suggesting that low $25(\mathrm{OH}) \mathrm{D}$ levels may be an independent, potentially modifiable, cardiovascular risk factor. ${ }^{3-11,17}$

The finding that the adverse cardiovascular effect of a low $25(\mathrm{OH}) \mathrm{D}$ level was increased in the analysis excluding those with cardiovascular-related morbidity is consistent with the notion that the full analysis is overadjusted. That is, if $25(\mathrm{OH}) \mathrm{D}$ levels are causally related to the onset of cardiovascular-related morbidity, then those with cardiovascular-related morbidity at baseline presumably developed those conditions, in part, because of low 25(OH)D levels. Thus, including those participants in the analysis and adjusting for those conditions result in partially adjusting for cardiovascular effects of $25(\mathrm{OH}) \mathrm{D}$ that had already occurred at baseline. In contrast, the analysis excluding those with baseline cardiovascular-related morbidity likely reflects a less-overadjusted estimate of the effects of $25(\mathrm{OH}) \mathrm{D}$ on cardiovascular mortality.

Prospective studies suggest that low levels of vitamin D precede the development of cardiovascular-related conditions, such as diabetes and hypertension. 6,32 Vitamin D may affect vascular endothelium directly through the renin-angiotensin axis ${ }^{12}$; through effects on vascular smooth muscle, including cell proliferation, ${ }^{13}$ inflammation, ${ }^{12}$ and thrombosis ${ }^{14}$; and through effects on hyperparathyroid hormone. ${ }^{15,16} \mathrm{We}$ did not assess these factors directly, although we found an inverse relationship between $25(\mathrm{OH}) \mathrm{D}$ levels and CRP.

Our second notable finding pertains to the potential contribution of vitamin $\mathrm{D}$ to racial differences in ageand sex-adjusted cardiovascular mortality. Controlling for the large differences by race in $25(\mathrm{OH}) \mathrm{D}$ levels yielded a significant attenuation in the association of race with cardiovascular mortality. In the model that included only exogenous variables (age, sex, month, and region), blacks had a $38 \%$ higher rate of cardiovascular mortality than whites, comparable to recently reported racial disparity in cardiovascular mortality. ${ }^{33}$ Adjustment for $25(\mathrm{OH}) \mathrm{D}$ levels reduced this excess risk by approximately $60 \%$. Inclusion of both $25(\mathrm{OH}) \mathrm{D}$ and poverty reduced the excess risk to 1.0 , suggesting that low 25(OH)D levels and poverty exert separate, additive effects on black cardiovascular mortality.

These findings are consistent with the notion that higher cardiovascular risk for blacks is partly related to lower levels of $25(\mathrm{OH}) \mathrm{D}$. Consistent with prior findings, ${ }^{34}$ race was strongly associated with low $25(\mathrm{OH}) \mathrm{D}$ levels. Such differences in levels by race have been reported in infancy. ${ }^{35,36}$ Lower levels among blacks potentially reflect decreased sun exposure, ${ }^{25}$ decreased sun absorption because of higher dermal melanin, ${ }^{23}$ and lower vitamin D intake. ${ }^{24}$ Supplements higher than those currently recommended would be needed to substantially increase levels among those in the lowest quartile. ${ }^{37,38}$

In an earlier study, Melamed et al observed an association between low 25(OH)D levels and all-cause mortality, but no significant effect on cardiovascular mortality. ${ }^{18}$ Using their analytic approach, we were able to produce comparable results. Two key differences between their and our analyses explain the discrepant results. Most importantly, they used the highest quartile of $25(\mathrm{OH}) \mathrm{D}$ for their reference group. As noted by Melamed et al and observed here (Table 2 and Figure 1), those in the highest quartile had an adjusted mortality rate slightly (but not significantly) higher than the middle two quartiles, and lower (but not significantly) than the bottom quartile; thus, their use of this referent masked significant differences between the lowest and other quartiles. Second, their analysis did not adjust for health status, which exhibits strong independent relationships with both $25(\mathrm{OH}) \mathrm{D}$ (Table 1) and mortality (Table 2).

There are several sources of potential residual confounding in our analysis. First, low 25(OH)D levels may represent a marker for poor health (inadequately controlled in this study) or poor health may result in reduced sun exposure and consequent lower $25(\mathrm{OH}) \mathrm{D}$ levels. Second, measurement error in recorded variables, changes in measures after the single baseline assessment, or unmeasured risk factors could confound the findings. Differences in risk associated with low 25(OH)D levels, however, were modest between the model including only exogenous variables ( IRR $=1.73)$ and the potentially overadjusted model including possible intervening factors $(I R R=1.40)$. The modest changes between a model with multiple measured potential confounders and one with only exogenous variables suggest that unmeasured confounders may not fully account for the significant effect associated with low 25(OH)D levels.

Besides unmeasured confounding factors and the challenge of disentangling confounding from mediating factors, the other key limitation of this study is potential misclassification of cause of death. Death certificate data coding corresponds reasonably well with hospital data, ${ }^{39}$ with overestimation for myocardial infarction. ${ }^{40}$ The National Center for Health Statistics has perturbed data in the NHANES-NDI file to enhance confidentiality, but direct comparisons with restricted data show similar results. ${ }^{41}$ Most important, errors in coding of deaths or perturbations of the data would bias results toward the null.

To date, there are limited data from randomized controlled trials (RCTs) regarding the impact of vitamin D supplementation on cardiovascular disease. A 
meta-analysis of RCTs of vitamin D supplementation for other purposes, such as improvement in bone density and reduction in fractures, showed a reduction in all-cause mortality. ${ }^{42}$ A small, short-term RCT involving cholecalciferol (vitamin $\mathrm{D}_{3}$ ) plus calcium vs calcium alone among elderly women with low 25(OH)D levels showed modest reductions in systolic blood pressure in those receiving the combined intervention. ${ }^{43}$ Three RCTs of a vitamin D analogue, paricalcitol, yielded reductions in proteinuria among patients with chronic kidney disease. ${ }^{44}$ Some have suggested that statins represent analogues of vitamin D. ${ }^{45}$ Thus, there is emerging evidence for a potential causal and remediable relationship between low vitamin D levels and cardiovascular-related disease.

These findings highlight the need for RCTs to assess the impact of vitamin D supplementation on the development of cardiovascular-related conditions and mortality. Such studies should include sufficient numbers of blacks to assess the potential for supplementation among those with low levels to improve cardiovascular outcomes and reduce disparities. In the absence of such trials, the current observational findings are suggestive only. Previous observational studies showed a relationship between other vitamins (eg, vitamin E and betacarotene) and cardiovascular mortality ${ }^{46-48}$ that were not borne out by subsequent RCTs. ${ }^{49,50}$

In conclusion, low $25(\mathrm{OH}) \mathrm{D}$ levels independently predict cardiovascular mortality in a national US sample, with an apparent threshold effect around the 25th percentile. High prevalence of low 25(OH)D levels among blacks appears to contribute to differences in black-white age- and sex- adjusted cardiovascular mortality. RCTs of vitamin D supplementation in those with low 25(OH)D levels are needed to determine whether optimization of these levels improves outcomes from cardiovascular mortality, particularly among blacks, who bear a disproportionate burden of cardiovascular disease.

To read or post commentaries in response to this article, see it online at http://www.annfammed.org/cgi/content/full/8/1/11.

Key words: Vitamin D; calcifediol; death; vitamin D deficiency; minority health; cardiovascular diseases

Submitted November 12, 2008; submitted, revised, February 10, 2009; accepted March 16, 2009.

Funding support: The study was supported by funding through The National Heart Lung and Blood Institute (1R01 HL081066-01A2).

\section{References}

1. Lee JH, O'Keefe JH, Bell D, Hensrud DD, Holick MF. Vitamin D deficiency an important, common, and easily treatable cardiovascular risk factor? J Am Coll Cardiol. 2008;52(24):1949-1956.
2. Kim DH, Sabour S, Sagar UN, Adams S, Whellan DJ. Prevalence of hypovitaminosis D in cardiovascular diseases (from the National Health and Nutrition Examination Survey 2001 to 2004). Am J Cardiol. 2008;102(11):1540-1544.

3. Martins $D$, Wolf $M$, Pan $D$, et al. Prevalence of cardiovascular risk factors and the serum levels of 25-hydroxyvitamin D in the United States: data from the Third National Health and Nutrition Examination Survey. Arch Intern Med. 2007;167(11):1159-1165.

4. Caan B, Neuhouser M, Aragaki A, et al. Calcium plus vitamin D supplementation and the risk of postmenopausal weight gain. Arch Intern Med. 2007;167(9):893-902.

5. Wang L, Manson JE, Buring JE, Lee IM, Sesso HD. Dietary intake of dairy products, calcium, and vitamin D and the risk of hypertension in middle-aged and older women. Hypertension. 2008;51(4):1073-1079.

6. Forman JP, Giovannucci E, Holmes MD, et al. Plasma 25-hydroxyvitamin D levels and risk of incident hypertension. Hypertension. 2007;49(5):1063-1069.

7. Pittas AG, Dawson-Hughes B, Li T, et al. Vitamin D and calcium intake in relation to type 2 diabetes in women. Diabetes Care. 2006;29(3):650-656.

8. Melamed ML, Muntner P, Michos ED, et al. Serum 25-hydroxyvitamin $D$ levels and the prevalence of peripheral arterial disease: results from NHANES 2001 to 2004. Arterioscler Thromb Vasc Biol. 2008;28(6):1179-1185.

9. de Boer IH, loannou GN, Kestenbaum B, Brunzell JD, Weiss NS. 25-Hydroxyvitamin D levels and albuminuria in the Third National Health and Nutrition Examination Survey (NHANES III). Am J Kidney Dis. 2007;50(1):69-77.

10. Wang TJ, Pencina MJ, Booth SL, et al. Vitamin D deficiency and risk of cardiovascular disease. Circulation. 2008;117(4):503-511.

11. Giovannucci E, Liu Y, Hollis BW, Rimm EB. 25-hydroxyvitamin D and risk of myocardial infarction in men: a prospective study. Arch Intern Med. 2008;168(11):1174-1180.

12. Li YC, Kong J, Wei M, Chen ZF, Liu SQ, Cao LP. 1,25-Dihydroxyvita$\min \mathrm{D}(3)$ is a negative endocrine regulator of the renin-angiotensin system. J Clin Invest. 2002;110(2):229-238.

13. Mantell DJ, Owens PE, Bundred NJ, Mawer EB, Canfield AE. 1 alpha,25-dihydroxyvitamin $\mathrm{D}(3)$ inhibits angiogenesis in vitro and in vivo. Circ Res. 2000;87(3):214-220.

14. Beer TM, Venner PM, Ryan CW, et al. High dose calcitriol may reduce thrombosis in cancer patients. Br J Haematol. 2006;135(3): 392-394.

15. Björkman MP, Sorva AJ, Tilvis RS. Elevated serum parathyroid hormone predicts impaired survival prognosis in a general aged population. Eur J Endocrinol. 2008;158(5):749-753.

16. Perkovic V, Hewitson TD, Kelynack KJ, Martic M, Tait MG, Becker G). Parathyroid hormone has a prosclerotic effect on vascular smooth muscle cells. Kidney Blood Press Res. 2003;26(1):27-33.

17. Dobnig H, Pilz S, Scharnagl H, et al. Independent association of low serum 25-hydroxyvitamin D and 1,25-dihydroxyvitamin D levels with all-cause and cardiovascular mortality. Arch Intern Med. 2008;168(12):1340-1349.

18. Melamed ML, Michos ED, Post W, Astor B. 25-hydroxyvitamin $D$ levels and the risk of mortality in the general population. Arch Intern Med. 2008;168(15):1629-1637.

19. National Center for Health Statistics. Health, United States, 2007. Hyattsville, MD: US Department of Health and Human Services, Centers for Disease Control and Prevention, National Center for Health Statistics; 2008

20. Thomas AJ, Eberly LE, Davey Smith G, Neaton JD, Stamler J. Race/ ethnicity, income, major risk factors, and cardiovascular disease mortality. Am J Public Health. 2005;95(8):1417-1423. 
21. Hozawa A, Folsom AR, Sharrett AR, Chambless LE. Absolute and attributable risks of cardiovascular disease incidence in relation to optimal and borderline risk factors: comparison of African American with white subjects-Atherosclerosis Risk in Communities Study. Arch Intern Med. 2007;167(6):573-579.

22. Seeman T, Merkin SS, Crimmins E, Koretz B, Charette S, Karlamangla $A$. Education, income and ethnic differences in cumulative biological risk profiles in a national sample of US adults: NHANES III (1988-1994). Soc Sci Med. 2008;66(1):72-87.

23. Chen TC, Chimeh F, Lu Z, et al. Factors that influence the cutaneous synthesis and dietary sources of vitamin D. Arch Biochem Biophys. 2007;460(2):213-217.

24. Moore CE, Murphy MM, Holick MF. Vitamin D intakes by children and adults in the United States differ among ethnic groups. J Nutr. 2005;135(10):2478-2485

25. Santmyire BR, Feldman SR, Fleischer AB Jr. Lifestyle high-risk behaviors and demographics may predict the level of participation in sun-protection behaviors and skin cancer primary prevention in the United States: results of the 1998 National Health Interview Survey. Cancer. 2001;92(5):1315-1324.

26. National Center for Health Statistics. Plan and Operation of the Third National Health and Nutrition Examination Survey, 1988-1994. Series I: Programs and Collection Procedures. Bethesda, MD: National Center for Health Statistics; 1994

27. Looker AC, Dawson-Hughes B, Calvo MS, Gunter EW, Sahyoun NR. Serum 25-hydroxyvitamin D status of adolescents and adults in two seasonal subpopulations from NHANES III. Bone. 2002;30(5):771-777.

28. National Center for Health Statistics. NHANES III Linked Mortality File. http://www.cdc.gov/nchs/rEd/nchs_datalinkage/nhanes3_data_ linkage_mortality_activities.htm. Accessed Jul 23, 2008.

29. Holford TR. The analysis of rates and of survivorship using log-linear models. Biometrics. 1980;36(2):299-305.

30. Clogg CC, Petkova E, Haritou A. Statistical methods for comparing regression coefficients between models. Am J Sociol. 1995;100(5): 1261-1293.

31. Fieller EC. Some problems in interval estimation. J Roy Statist Soc Ser B Methodological. 1954;16:175-183.

32. Forouhi NG, Luan J, Cooper A, Boucher BJ, Wareham NJ. Baseline serum 25-hydroxy vitamin $d$ is predictive of future glycemic status and insulin resistance: the Medical Research Council Ely Prospective Study 1990-2000. Diabetes. 2008;57(10):2619-2625.

33. Rosamond W, Flegal K, Furie K, et al.; American Heart Association Statistics Committee and Stroke Statistics Subcommittee. Heart disease and stroke statistics-2008 update: a report from the American Heart Association Statistics Committee and Stroke Statistics Subcommittee. Circulation. 2008;117(4):e25-e146

34. Zadshir A, Tareen N, Pan D, Norris K, Martins D. The prevalence of hypovitaminosis D among US adults: data from the NHANES III. Ethn Dis. 2005;15(4 Suppl 5):S5-S101.

35. Bodnar LM, Simhan HN, Powers RW, Frank MP, Cooperstein E, Roberts JM. High prevalence of vitamin D insufficiency in black and white pregnant women residing in the northern United States and their neonates. J Nutr. 2007:137(2):447-452.
36. Rovner AJ, O'Brien KO. Hypovitaminosis D among healthy children in the United States: a review of the current evidence. Arch Pediatr Adolesc Med. 2008;162(6):513-519.

37. Heaney RP, Davies KM, Chen TC, Holick MF, Barger-Lux MJ. Human serum 25-hydroxycholecalciferol response to extended oral dosing with cholecalciferol. Am J Clin Nutr. 2003;77(1):204-210.

38. Rajakumar K, Fernstrom JD, Holick MF, Janosky JE, Greenspan SL. Vitamin D status and response to Vitamin $D(3)$ in obese vs. nonobese African American children. Obesity (Silver Spring). 2008;16(1): 90-95.

39. Goraya TY, Jacobsen SJ, Belau PG, Weston SA, Kottke TE, Roger VL. Validation of death certificate diagnosis of out-of-hospital coronary heart disease deaths in Olmsted County, Minnesota. Mayo Clin Proc. 2000:75(7):681-687.

40. Coady SA, Sorlie PD, Cooper LS, Folsom AR, Rosamond WD, Conwill DE. Validation of death certificate diagnosis for coronary heart disease: the Atherosclerosis Risk in Communities (ARIC) Study. J Clin Epidemiol. 2001;54(1):40-50.

41. Wheatcroft G, Cox CS, Kochner KA. Comparative Analysis of the NHANES III Public-Use and Restricted-Use Linked Mortality Files. Hyattsville, MD: National Center for Health Statistics; 2007.

42. Autier P, Gandini S. Vitamin D supplementation and total mortality: a meta-analysis of randomized controlled trials. Arch Intern Med. 2007;167(16):1730-1737.

43. Pfeifer M, Begerow B, Minne HW, Nachtigall D, Hansen C. Effects of a short-term vitamin $\mathrm{D}(3)$ and calcium supplementation on blood pressure and parathyroid hormone levels in elderly women. J Clin Endocrinol Metab. 2001;86(4):1633-1637.

44. Agarwal R, Acharya M, Tian J, et al. Antiproteinuric effect of oral paricalcitol in chronic kidney disease. Kidney Int. 2005;68(6): 2823-2828.

45. Grimes DS. Are statins analogues of vitamin D? Lancet. 2006:368 (9529):83-86.

46. Gaziano JM, Manson JE, Branch LG, Colditz GA, Willett WC, Buring JE. A prospective study of consumption of carotenoids in fruits and vegetables and decreased cardiovascular mortality in the elderly. Ann Epidemiol. 1995;5(4):255-260.

47. Kushi LH, Folsom AR, Prineas RJ, Mink PJ, Wu Y, Bostick RM. Dietary antioxidant vitamins and death from coronary heart disease in postmenopausal women. N Engl J Med. 1996;334(18):1156-1162.

48. Klipstein-Grobusch K, Geleijnse JM, den Breeijen JH, et al. Dietary antioxidants and risk of myocardial infarction in the elderly: the Rotterdam Study. Am J Clin Nutr. 1999;69(2):261-266

49. Shekelle PG, Morton SC, Jungvig LK, et al. Effect of supplemental vitamin $\mathrm{E}$ for the prevention and treatment of cardiovascular disease. J Gen Intern Med. 2004;19(4):380-389.

50. Heart Protection Study Collaborative Group. MRC/BHF Heart Protection Study of antioxidant vitamin supplementation in 20,536 high-risk individuals: a randomised placebo-controlled trial. Lancet. 2002;360(9326):23-33 